
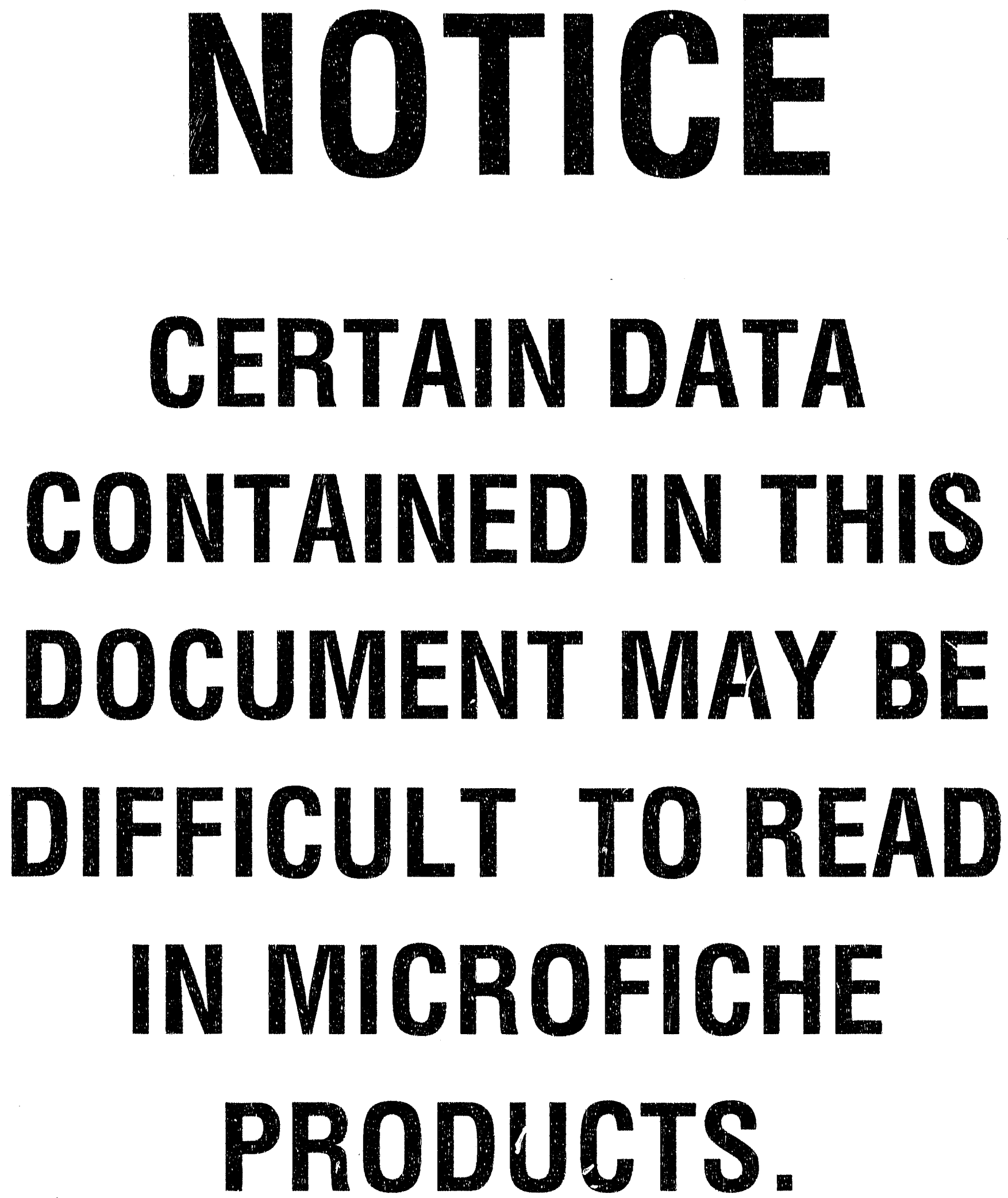


\section{Conf- $9205196--4$ \\ F.xkl. fibst.}

PNL-SA--20446

DE92 019139

TANDEM MASS SPECTROMETRY OF MULTIPLY

CHARGED PROTEINS WITH ELECTROSPRAY

IONIZATION

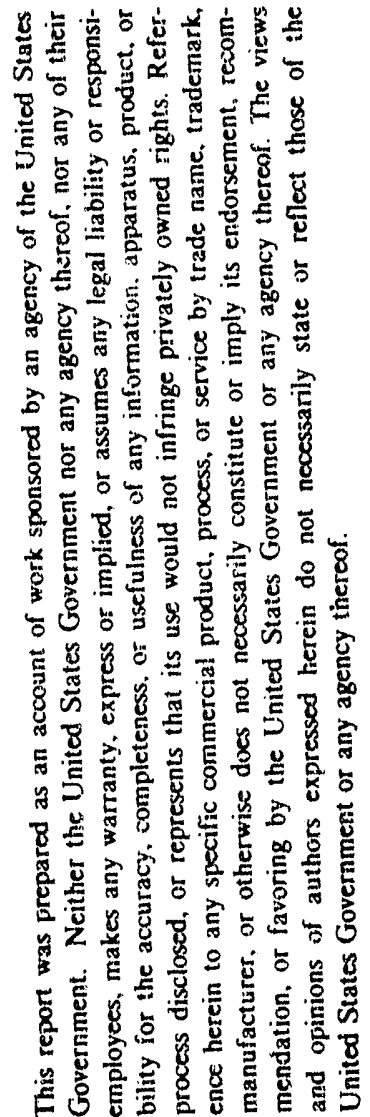
J. A. 100
R. D. Smith

June 1992

Presented at the
American Society for Mass Spectrometry 40 th
Conference on Mass Spectrometry and Allied Topics May 31 - June 5, 199 ?

Washington, D.C.

Work supported by

the U.S. Department of Energy under Contract DE-ACO6-76RLO 1830

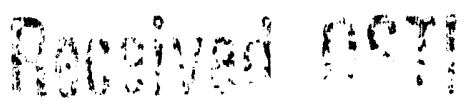

AU6 111992

Pacific Northwest Laboratory

Richland, Washington 99352

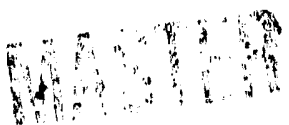




\title{
Tandem Mass Spectrometry of Multiply Charged Proteins
with Electrospray Ionization
}

\author{
Joseph A. Loo and Richard D. Smith \\ Chemical Sciences Department \\ Pacific Northwest Laboratory \\ P. O. Box 999, Richland, WA 99352
}

In conjunction with proteolytic digestion and landern mass spectrometry (MS/MS), complete sequence information for proteins can be obtained. However, a potential gair in speed and sensitivity can be realized from collisionally activated dissociation (CAD) of intact proteins, provided process of large molecules are obtained.

We have previously demonstrated that limited sequence information for proteins as large as ribonuclease $A(13.7 \mathrm{kDa})$ [1] and serum albumins $(66 \mathrm{kDa})$ [2] can be oblained from CAD of compounds, difficulties in es generated by electrospray ionization (ESI). Even for "known" possibility of multiply charged product ions. However proban MS/MS spectra arise because of the searching for leatures common 10 most MS/MS spect, prnbable assignmenls can be determined by interpretation of CAD mass spectra of multiply charged precuisor ions include:

- A progression of product ion charge states (e.g., $\mathrm{y}_{25}{ }^{2+}, \mathrm{y}_{25}{ }^{3+}, \mathrm{y}_{25}{ }^{4+}$ ).

- Product ion series (e.g., $\left.y_{2,3}{ }^{2+}, y_{26}{ }^{2+}, y_{27}{ }^{2+}, \ldots\right)$.

- MS/MS of product ions ("MS/MS/MS") to confirm assignments (and provide additional interface by increasing the voltage differen be generated in the atmospheric pressure/vacuum quadrupole collision cell (Q2). Fragment ions produced the nozzle and skimmer elements, or in the Q1 and be further dissociated in Q2.

homology) help to identify the approximate location related molecules (e.g., variants, sequence product ion due to the expe ted shifts in $m / z$.

Dissociation of bexine carbenic anhydrase (29 kDa, 259 residues) produces a progression of charge states for several product ions (e.g., $\left.y_{67}{ }^{6+}, y_{67} 7^{7+}, y_{67}{ }^{8+}\right)$. Fragmentation is direcled towards the COOH-terminal region of the polypeptide. Dissociation of the amide bond to a proline residue is lavored for a number of proteins sludied, especially carbonic anhydrase.

The presence of complementary ic n pairs, which in sum (mass and charge) account for the entire molecule, alleviates some problems of interpretatioil of tandem mass spectra. Simple alaorithms can determine whether two product ions are possibly complementary. MS/MS of the $(\mathrm{M}+34 \mathrm{H})^{34+}$ of carbonic anhydrase (Fig. 1) produces several sets of complementary ion pairs (e.g., $y_{67}{ }^{7+} \ldots b_{192}{ }^{27+}$, $\left.y_{61}{ }^{7+}+b_{198^{27+}} \cdot y_{67}{ }^{8+}+b_{192^{26+}} \cdot y_{61}{ }^{8+}-b_{198}{ }^{26+}\right)$

Transferrins are iron-hinoing glycoproteins of approximately $79 \mathrm{kDa}$, widely distributed in the physiological fluids of vertebrates. The available amino acid sequences for several species show a dissociation in the atmospheric pressure/vact). Product ions can be produced by molecular homology, these product ions ions from the $\mathrm{NH}_{2}$-terminal region be compared and assigned as a series of multiply charged $b_{n}$ unknown, the fragmentation pattern is condue 60. Althnught the sequenco ist wovitie irarisierrin is assigned from the measured peak spacings. 
Reduction of disulfide bonds with 1,4-dithiothreitol expecledly allows higher charged molecules to be produced, and unexpectedly releases a small, $6-8 \mathrm{kDa}$ peptide from the COOH-terminus for the mammalian transferrin proteins studied (Fig. 2). Tandem mass spectromelry data for the released peplide from human transferrin is consistent with the expected amino acid sequence for the $\mathrm{COOH}$ lerminus.

$\begin{array}{lccc} & \text { Measured } M_{r} \text { of COOH-Terminal Transferrin Peptide } \\ \text { Species } & M_{r} \text { (exp }(l) & M_{r} \text { (sequence) } & \text { Residues } \\ \text { Human } & 6485.1 \pm 0.4 & 6484.4 & 624-679 \\ \text { Rabbit } & 7752.6 \pm 0.6 & 7752.9 & 609-675 \\ \text { Bovine } & 6066.2 \pm 0.6 & \text { n.a } & \text { n.a }\end{array}$

Dissociation of large, multiply charged proteins can be induced. However, for CAD of larger proteins, higher $m / z$ resolution (e.g. Fourier transform MS) may be necessary to assign product ion charge states.

References:

[1] J.A. Loo, C.G. Edmonds, and R.D. Smith, Science 1990, 248, 201-204.

(2) J.A. Loo, C.G. Edmonds, and R.D. Smith, Anal. Chem. 1991, 63, 2488-2499.

Pacific Northwest Laboratory is operated for the U.S. Department of Energy by Battelle Memorial Institute under Contract DE-AC06-76RLO 1830.

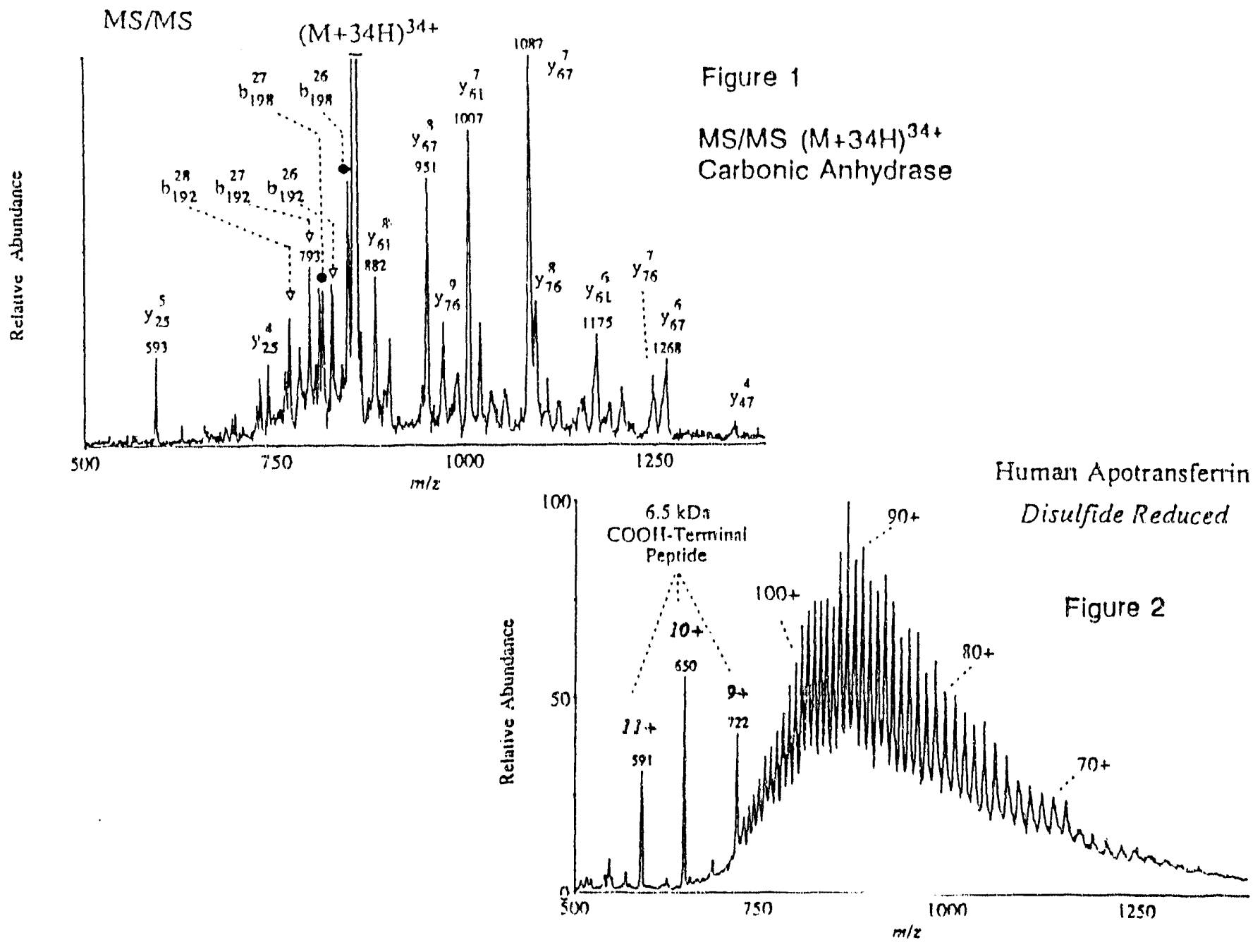



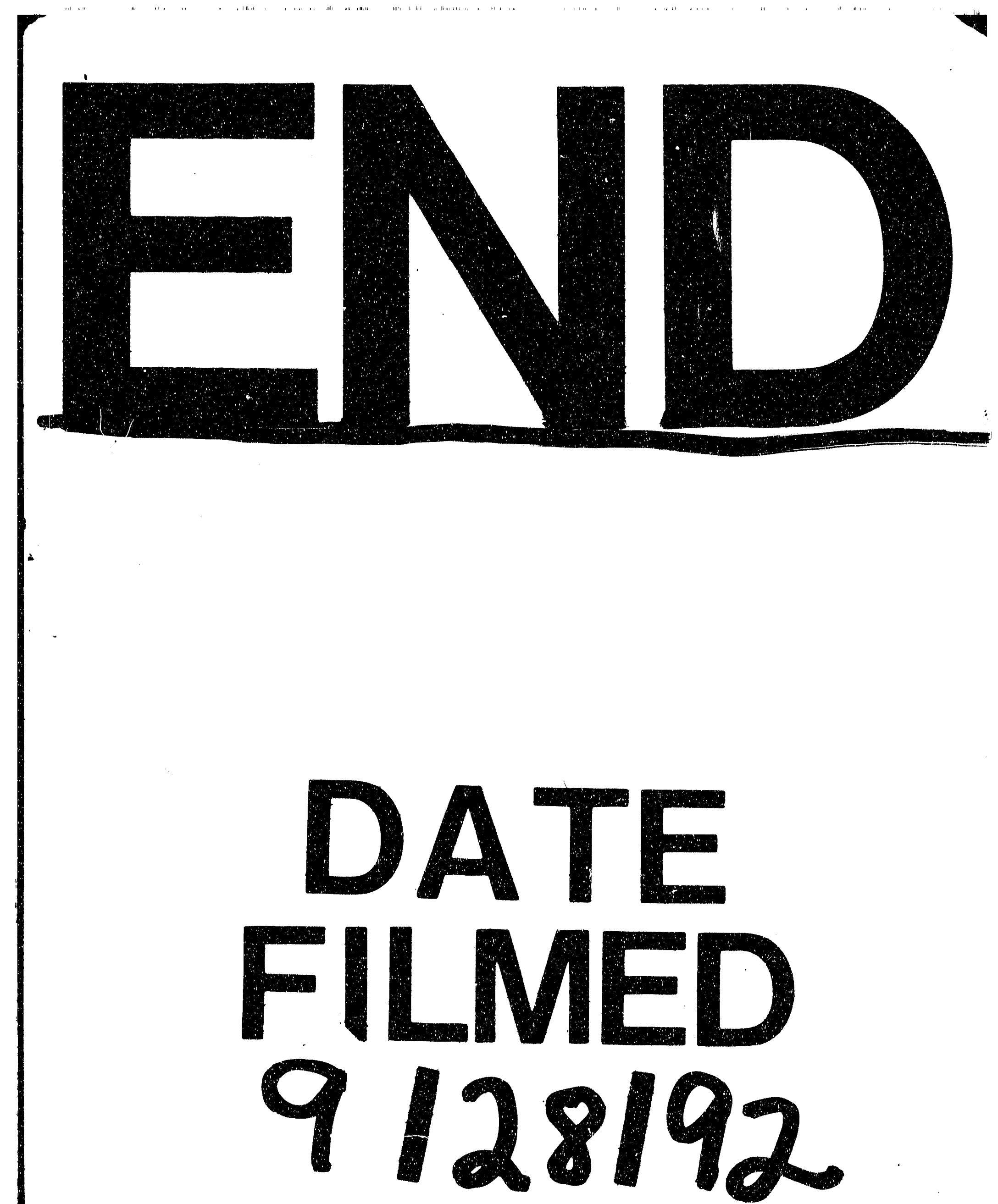


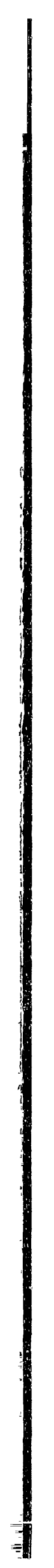

